Obere Extremität 2019 $\cdot 14: 103-109$ https://doi.org/10.1007/s11678-019-0509-1 Received: 31 October 2018

Accepted: 1 February 2019

Published online: 25 February 2019

(c) The Author(s) 2019
Mirjam Schirren · Georg Siebenbürger • Evi Fleischhacker · Niklas Biermann · Tobias Helfen · Wolfgang Böcker · Ben Ockert 1

Sektion Schulter- und Ellenbogenchirurgie, Klinik für Allgemeine, Unfall- und Wiederherstellungschirurgie, Klinikum der Universität München, Ludwig-Maximilians-Universität, Munich, Germany

\section{Anterior fracture dislocation of the proximal humerus}

\section{Management and treatment results}

\section{Anterior fracture dislocations are characterized by fracture of the proximal humerus combined with dislocation of the head fragment anterior to the glenoid fossa. Frequently, the anteroinferior soft- tissue envelope is disrupted, thus the risk of devascularization of the humeral head is high. Fracture dislocations are regarded to be among the most severe forms of proximal humeral fractures and consequently represent a treatment challenge.}

In contrast to isolated fractures of the greater tubercle with glenohumeral dislocation, three- and four-segment fracture dislocations of the proximal humerus are rare $[4,5]$. As the humeral head fragment is dislocated and locked anterior to the glenoid, reduction forces are not transmitted via the surgical neck, and therefore an attempt for closed reduction typically fails [6]. Instead, open reduction is required in order to facilitate reduction of the humeral head; however, care must be taken not to cause further harm to neurovascular structures by any means [7]. While rates of concomitant brachial plexus lesions and vascular injuries are higher for fracture dislocations, further fracture displacement and iatrogenic nerve injuries are reported in the literature [8-11].

Owing to the disruption of the anteroinferior soft-tissue envelope, anterior fracture dislocation is associated with a high risk of avascular necrosis (AVN) and nonunion following open reduction and internal fixation (ORIF;
[1-3]). Therefore, humeral head replacement (HSA) was long suggested as the treatment of choice for anterior fracture dislocation by several authors $[12,13]$. However, while this removes the risk of nonunion and osteonecrosis, it does carry its own significant risk of early complications, including tuberosity nonunion and malunion [14]. Furthermore, from reports of several studies, functional outcomes following humeral head replacement are often unsatisfactory $[15,16]$. Therefore, it is still under debate whether hemiarthroplasty should be favored over ORIF [3, 17].

Over the past decade, reverse shoulder arthroplasty (RSA) has been established as a first-line treatment in proximal humeral fractures in elderly patients $[18$, 19]. However, long-term follow-up studies are lacking and the results of RSA in anterior fracture dislocations may differ. To date, there are only few data available describing outcomes of RSA in a larger cohort of patients with anterior fracture dislocation. [20, 21]. Thus, the aim of this study was to evaluate functional outcomes, complications, and revision rates of ORIF, HSA, and RSA in anterior fracture dislocations and compare the results. We hypothesized that functional outcomes following HSA would be inferior to ORIF and RSA and that there would be complications related to each treatment modality.

\section{Material and methods}

\section{Patient collective}

Between January 2002 and December 2016, 1154 patients with a proximal humeral fracture were treated operatively in a level-1 trauma university hospital. Patients were prospectively enrolled in the institutional database and followed up longitudinally. For the purpose of this study, we retrospectively evaluated patients with anterior fracture dislocations of the proximal humerus. We considered only three- and foursegments fracture dislocations of the proximal humerus in which the head fragment was fully dislocated anterior to the glenoid fossa. We therefore excluded all proximal humeral fractures without glenohumeral dislocation. Furthermore, we excluded simple shoulder dislocations and isolated fractures of the greater tubercle with glenohumeral dislocation, since they represent a different entity. Additionally, fractures of the humeral shaft with concomitant glenohumeral dislocation were excluded, as were posterior shoulder dislocations with reverse Hill-Sachs lesion; posterior fracture dislocations and isolated fractures of the lesser tubercle with posterior dislocation were also excluded.

In total, 96 patients (8.3\%) matching the aforementioned criteria, were identified, who were treated operatively for an anterior fracture dislocation of the proximal humerus. In 81 patients (7.1\%) a minimum follow-up of 24 months was carried out, and the data of these patients 

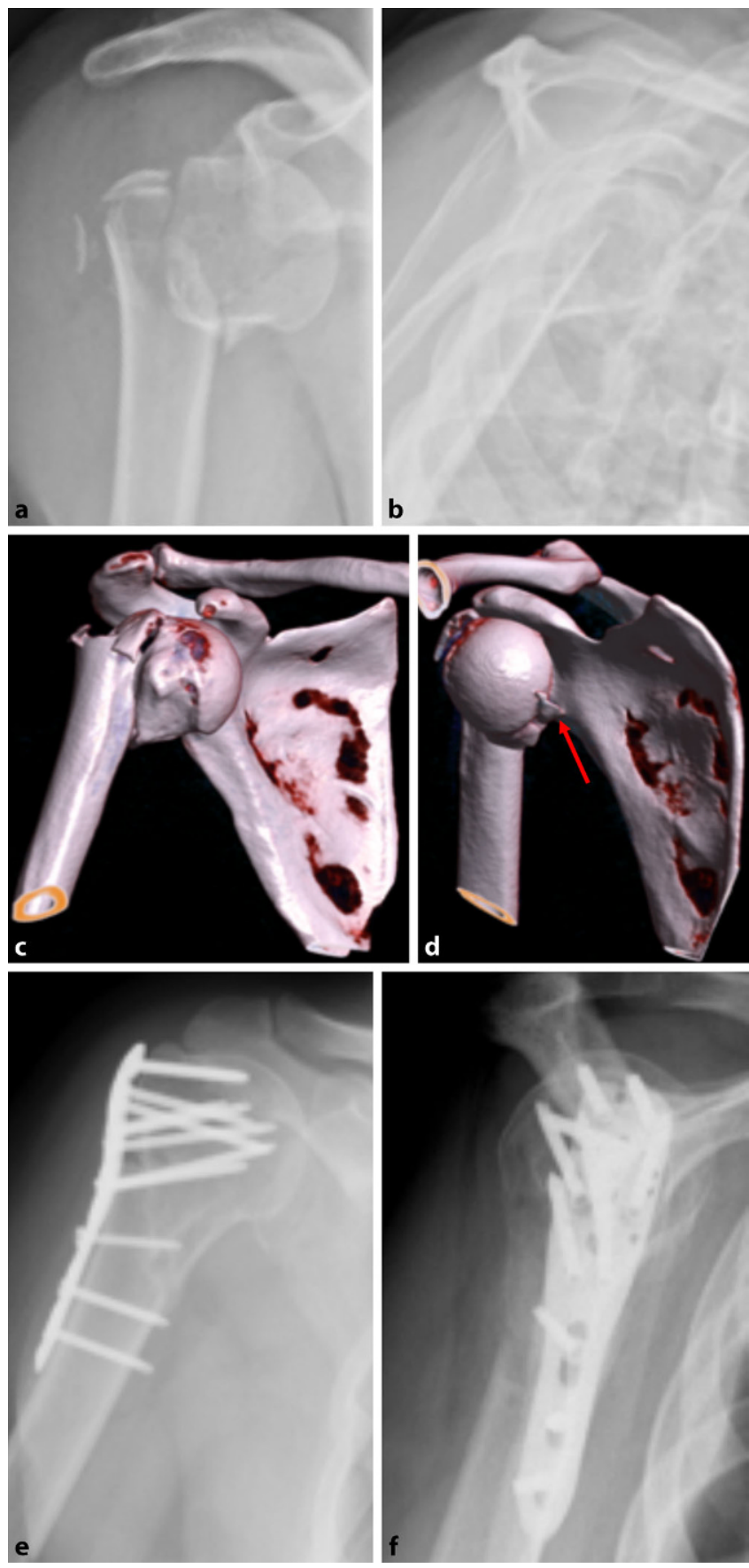

Fig. $1<$ Robinson type I anterior fracture dislocation in a 52-year-old female patient treated by open reduction with internal fixation (ORIF). Anteroposterior (a) and outlet view (b) radiographs; computed tomography scans (c, d). d Note anterior glenoid rim fracture ("bony Bankart," arrow). Postoperative radiographs after surgical treatment by ORIF (e-f) showing fracture healing and a well-centered glenohumeral joint

were analyzed for this study (follow-up rate: $84.4 \%)$.

\section{Surgical treatment}

Surgical treatment was chosen depending on the patients' age and comorbidities, local bone quality, and history of previous shoulder injuries or concomitant lesions of the shoulder. Patients were treated by one of three procedures: open reduction and internal fixation
(ORIF) using locking plates (proximal humerus interlocking system PHILOS DePuySynthes ${ }^{\circledR}$, Umkirch, Germany), humeral head resection and replacement by anatomic fracture hemiprosthesis (HSA), or reversed shoulder arthroplasty (RSA; Aequalis fracture hemiarthroplasty or reverse fracture arthroplasty, Wright Medical-Tornier ${ }^{\circledR}$, Burscheid, Germany). All operations were performed with the patient in the beachchair position under general anesthesia.
Antibiotic prophylaxis with third-generation cephalosporin was administered to all patients. Interscalene block anesthesia was carried out if patients agreed to it.

All operations were conducted by board-certified orthopedic trauma surgeons. Dissection was performed via a deltopectoral approach and by opening the rotator interval between the subscapularis and supraspinatus tendon, prior to bluntly reducing the head fragment. In ORIF, the fracture was then anatomically reduced and fixed by at least six locking screws into the humeral head and three screws to the humeral shaft, as described previously $[22,23]$. Screws were placed meticulously in the humeral head within $5 \mathrm{~mm}$ of the subchondral layer. Nonresorbable sutures (Nr. 5 Fiber Wire, Arthrex ${ }^{\circledR} \mathrm{GmbH}$, Munich, Germany) were used predominantly through the insertion of the rotator cuff to secure the reduction of the tubercles.

In all cases of fracture arthroplasty, both the major and the lesser tubercle were fixed anatomically (Aequalis fracture) or extra-anatomically (Aequalis reverse) with nonresorbable horizontal and vertical sutures (Nr. 5 Fiber Wire, Arthrex ${ }^{\circledR} \mathrm{GmbH}$, Munich, Germany). All surgeries were performed within the first 7 days of trauma and all but one ORIF were performed within the first $24 \mathrm{~h}$. Postoperative immobilization was heterogeneous over the study period; however, either a Gilchrist sling or an abduction pillow were used for early postoperative immobilization of the arm. On the first day after surgery, passive and active-assisted range of motion exercises were started under supervision by a physical therapist and was continued for at least 6 weeks after the operation.

\section{Outcome assessment}

All patients underwent routine clinical and radiological follow-up at 6 weeks as well as at 3, 6, and 12 months and additionally at a minimum of 24 months for the purpose of this study. At each followup, we assessed the functional result by using the Constant score (CS). To achieve better comparability, the age-and gendernormalized CS (nCS) was calculated. The 
Obere Extremität 2019 · 14:103-109 https://doi.org/10.1007/s11678-019-0509-1

(c) The Author(s) 2019

M. Schirren · G. Siebenbürger · E. Fleischhacker · N. Biermann · T. Helfen · W. Böcker · B. Ockert

\section{Anterior fracture dislocation of the proximal humerus. Management and treatment results}

\section{Abstract}

Background. Anterior fracture dislocations are among the most severe forms of proximal humeral fractures. Because of potential devascularization of the humeral head, it is unclear whether open reduction and internal fixation (ORIF) offers superior results to primary hemiarthroplasty (HAS) or reverse shoulder arthroplasty (RSA).

Methods. We retrospectively compared functional outcomes, complications, and revision surgeries after ORIF, HSA, and RSA in 81 patients with anterior fracture dislocations. Functional results were assessed with the ageand gender-normalized Constant Score (nCS). Results. Of 81 anterior fracture dislocations, 40 (49.4\%) were treated by ORIF (mean age $61.5 \pm 13.9$ years, range 29-89), 19 (12.3\%) by HSA (mean age $71.6 \pm 10.1$ years, range
53-85), and 22 (27.2\%) by RSA (mean age $79.8 \pm 10.8$ years, range $58-91$ ). Of 81 patients (75.8\% women, mean age: $67.4 \pm 12.5$ years, range 29-91 years), the mean nCS after $3.4 \pm 2.9$ years of follow-up was $63.4 \pm 10.3$ after ORIF, $52.4 \pm 12.9$ after HSA, and $74.5 \pm 11.1$ after RSA (ANOVA, $p=0.001$ ). The complication rate in ORIF procedures was $22.5 \%$ (secondary displacement $n=2$, avascular necrosis $n=7$ ), in HSA, $36.8 \%$ (tubercle dislocation $n=4$, tubercle resorption $n=2$, septic loosening $n=1$ ), and RSA, $13.6 \%$ (acromial fracture $n=1$, tubercle displacement $n=1$, tubercle resorption, $n=1 ; p<0.001$ ). Avascular necrosis was observed in $17.5 \%$ of cases following a primary head-preserving treatment.
Conclusion. Treatment of anterior fracture dislocations is demanding. Open anatomic reduction and internal fixation can lead to good and excellent functional outcomes in young patients with good bone quality and should be performed in these patients as soon as possible. Elderly and frail patients may profit from RSA as a primary treatment. HSA should be reserved for cases where anatomic reduction and stable fixation in patients $<65$ years has failed; however, functional outcomes are poor.

\section{Keywords}

Humeral fracture $\cdot$ Shoulder - Avascular necrosis - Osteosynthesis · Arthroplasty

\section{Anteriore Luxationsfraktur des proximalen Humerus. Versorgung und Therapieergebnisse}

\section{Zusammenfassung}

Hintergrund. Die vordere Luxationsfraktur des proximalen Humerus (A011-B3/C3) zählt zu den komplexen Formen der proximalen Humerusfraktur. Aufgrund der potenziellen Devaskularisierung des Humeruskopfes ist bisher unklar, ob eine Frakturrekonstruktion angestrebt werden sollte und wie die Ergebnisse im Vergleich zur Frakturhemiprothese und zur primären inversen Frakturprothese ausfallen.

Methodik. Klinische Ergebnisse, Komplikationen und notwendige Revisionseingriffe von Patienten nach operativer Behandlung einer anterioren Humeruskopfluxationsfraktur wurden retrospektiv ausgewertet. Ergebnisse nach offener Frakturreposition und Osteosynthese (ORIF) wurden mit Ergebnissen nach Hemiprothese (HSA) und nach inverser Frakturprothese (RSA) verglichen. Die funktionellen Ergebnisse wurden anhand des in Bezug auf Alter und Geschlecht normalisierten Constant Score (nCS) ermittelt.
Ergebnisse. Es wurden 40 von 81 anterioren Humeruskopfluxationsfrakturen $(49,4 \%)$ mittels ORIF (mittleres Alter: 61,5 $\pm 13,9$; 29-89 Jahre), 19 (12,3\%) mittels HSA (mittleres Alter: 71,6 $\pm 10 ; 53-85$ Jahre) und $22(27,2 \%)$ mittels RSA (mittleres Alter: 79,8 $\pm 10,8 ; 58-91$ Jahre) versorgt. Von 81 Patienten $(75,8 \%$ Frauen, mittleres Alter: $67,4 \pm 12,5$ Jahre) betrug der mittlere nCS nach durchschnittlich 3,4 $\pm 2,9$ Jahren bei Patienten nach ORIF $63,4 \pm 10,3$, nach HSA 52,4 $\pm 12,9$ und nach RSA 74,5 $\pm 11,1$ (ANOVA, $p=0,001$ ). Die Komplikationsraten betrugen für ORIF 22,5\% (2-mal sekundäre Dislokation, 7-mal avaskuläre Nekrose), für HSA 36,8 \% (4-mal Tuberkuladislokation, 2-mal Tuberkularesorption, einmal septische Lockerung) und für RSA 13,6\% (einmal Akromionfraktur, einmal Tuberkuladislokation, einmal Tuberkularesorption; $p<0,001)$. Eine avaskuläre Nekrose des Humeruskopfes wurde in 17,5\% der Fälle nach primär kopferhaltender Versorgung beobachtet.
Schlussfolgerung. Die Therapie der Humeruskopfluxationsfraktur ist anspruchsvoll. Mittels ORIF lassen sich bei jungen Patienten mit guter Knochenqualität gute bis exzellente klinische Ergebnisse erzielen, sie sollte daher bei diesen Patienten zeitnah angestrebt werden. Bei älteren und gebrechlichen Patienten mit reduzierter Knochenqualität ist die Versorgung mit einer RSA vorzuziehen, da sie gute Ergebnisse bei niedriger Komplikationsrate ermöglicht. Die HSA ist als Reserveoption anzusehen, wenn eine anatomische Kopfrekonstruktion und stabile Osteosynthese bei Patienten $<65$ Jahren nicht gelingt, da die klinischen Ergebnisse häufig schlecht ausfallen.

\section{Schlüsselwörter}

Humerusfraktur · Schulter · Avaskuläre Knochennekrose - Osteosynthese . Frakturendoprothetik primary outcome parameter was the nCS after 24 months of follow-up. Postoperative radiographs in anterior-posterior view and outlet view were assessed for fracture healing, secondary fracture dislocation, cut-out of screws, AVN of the humeral head, nonunion or malunion of the fracture, and implant failure (loosen- ing, break of implant, malposition of implant). In the cases of arthroplasty, tubercula displacement, resorption of tubercula, implant migration and loosening were further analyzed. Depending on the type of complication, different revision strategies were noted, which included: early partial or complete hardware re- moval, re-osteosynthesis, conversion to HSA or RSA.

\section{Statistical analysis}

The data were collected in a Microsoft ${ }^{\circledR}$ Access database and analyzed using the SPSS software package (SPSS Inc., 

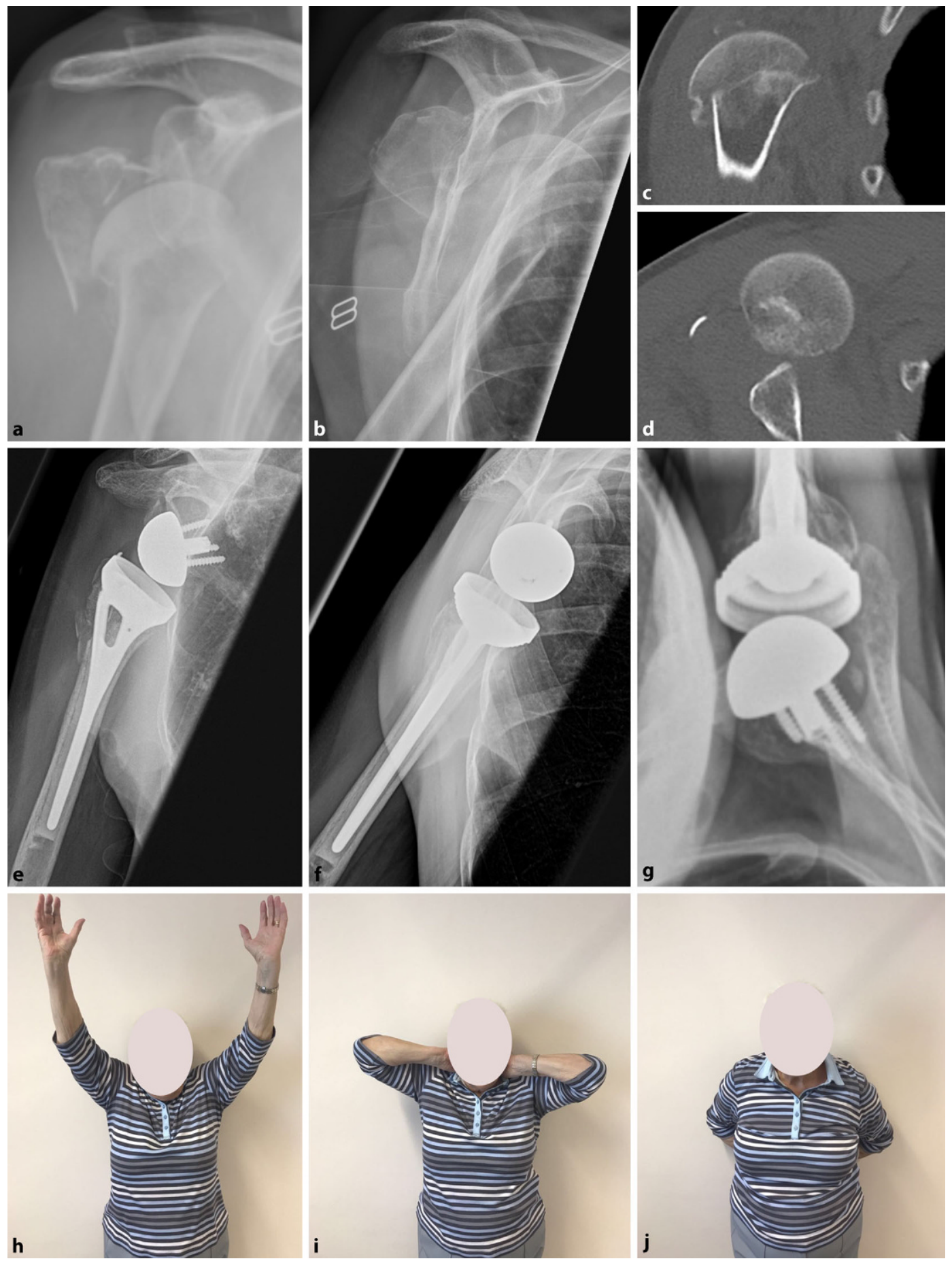

Fig. $2<$ Robinson type II anterior fracture dislocation in a 79-year-old female patient treated by reverse shoulder arthroplasty (RSA). Anteroposterior (a) and outlet view (b) radiographs; computed tomography scans (c, d). Note disruption of the medial hinge (c). Postoperative radiographs after surgical treatment by RSA (e-g) showing extra-anatomic healing of the lesser and major tubercle. Clinical outcome 1 year after surgery $(\mathbf{h}-\mathbf{j})$

Chicago, IL, USA). We determined a significance level of $95 \%(p \leq 0.05)$. For categorical data, results were compared using the chi-square test or the Fisher exact test, for continuous data by use of the Mann-Whitney $U$ test, and for interval-scaled variables, Pearson's or Spearman's bivariate correlation. A oneway ANOVA test was used to compare differences between groups. This was a retrospective, nonrandomized, comparative cohort study with a level of evidence of type III.

\section{Results}

Data of 81 patients $(75.8 \%$ women, mean age of women: $71 \pm 10.5$ years, mean age of men: $59.6 \pm 15.2$ years, range: 29-91 years) were analyzed for this study. In 32 cases (39.5\%), the injury was classified as a Robinson type I anterior fracture dislocation (mean age of patients: $59.8 \pm 9.6$ years), and in 49 (60.5\%) cases, a Robinson type II anterior fracture dislocation was present (mean age of patients: $73.6 \pm 12.5$ years). In $67.9 \%$ of cases, the fracture comprised a three-part greater tuberosity surgical neck type fracture and 59.7\% 


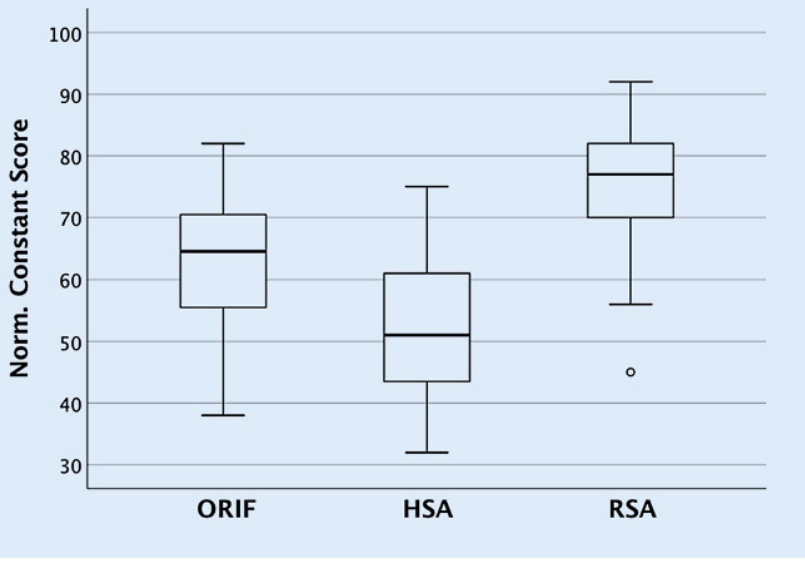

\section{Discussion}

Fig. $3<$ Mean normalized Constant score. ORIF open reduction with internal fixation, HSA hemiarthroplasty, $R S A$ reverse shoulder arthroplasty of fractures were classified as AO11-C3 fractures. In $28 \%$ of cases, an additional glenoid fracture was present.

Of 81 anterior fracture dislocations, $40(49.4 \%)$ were treated by ORIF (mean age: $61.5 \pm 13.9$ years, range: 29-89), 19 (12.3\%) by HSA (mean age: $71.6 \pm 10.1$ years, range: 53-85) and $22(27.2 \%)$ by RSA (mean age: $79.8 \pm 10.8$ years, range: $58-91$ ). In patients younger than 60 years, osteosynthesis was the most frequently performed treatment $(82.4 \%)$, whereas in patients aged 60 years or older arthroplasty was used (71.2\%) most frequently. In Robinson type I fractures (• Fig. 1), $68.8 \%$ were treated by ORIF, $28.1 \%$ by has, and $3.1 \%$ by RSA; in Robinson type II fractures $36.7 \%$ were treated by ORIF, $20.4 \%$ by has, and $42.9 \%$ by RSA (• Fig. 2). In AO11-C3-fractures, $24.4 \%$ were treated by ORIF, $45.9 \%$ by HSA, and $29.7 \%$ by RSA. Osteosynthesis was performed at an average of $0.1 \pm 1.3$ days, HSA an average of $2.8 \pm 6.7$ days, and RSA at an average of $4.1 \pm 3.8$ days after admission from the emergency department.

After $3.4 \pm 2.9$ years of follow-up, the mean nCS was $65.4 \pm 12.3$. There was no significant difference in functional outcomes comparing AO11-B3 and AO11C3 fractures $(p=0.375)$ and Robinson type I and II fractures $(p=0.079)$. Functional outcome differed significantly depending on the treatment modality. The mean nCS following ORIF was $63.4 \pm 10.3$, the mean nCS following HSA was $52.4 \pm 12.9$, and the mean nCS following RSA was $74.5 \pm 11.1 \quad(p=0.001$,

- Fig. 3). In patients younger than
60 years the functional results were worse than in patients aged 60 years or older with a mean nCS of $62.8 \pm 18.3$ versus $71.2 \pm 12.7$, respectively $(p=0.23)$.

Overall, there was a complication rate of $23.5 \%$. In the ORIF group, complications were observed in nine cases $(22.5 \%$; - Table 1) with two cases of secondary displacement and seven cases (17.5\%) of AVN. Avascular necrosis occurred in one of 22 (4.5\%) cases of ORIF for Robinson type I fracture dislocation, but in six of 18 (33\%) cases after ORIF for Robinson type II fracture $(p=0.035)$.

Following treatment by HSA, complications were observed in seven cases (36.8\%), including tubercle dislocation in four cases $(21.1 \%)$, tubercle resorption in two cases (10.5\%), and one case of septic loosening (5.3\%; - Table 2). Three complications (13.6\%) were noted after RSA, of which one case was an acromial fracture, one case of tubercle displacement, and one case of tubercle resorption (4.5\% each, - Table 2). There was no instability or glenoid loosening; however, inferior notching was present in eight cases (six cases Sirveaux grade I and two cases Sirveaux grade II). Overall, there was no nerve injury or postoperative hemorrhage. Revision osteosynthesis was performed in one case (1.2\%), conversion to HSA was performed in one case (1.2\%), and conversion to RSA was performed in three cases (3.7\%). Following HSA, a revision to RSA was carried out three times (3.7\%) and fixation of a displaced tubercle in one case $(1.2 \%)$. There was no revision surgery following primary treatment by RSA (• Table 2 ).
Anterior fracture dislocations are regarded to be among the most severe forms of proximal humeral fractures. Because of the locked dislocation and potential devascularization of the humeral head, treatment of three- and four-part fracture dislocations is technically demanding. Owing the comparative rarity of this injury pattern, few surgeons gain sufficient experience in managing these injuries to be confident in their assessment and treatment [24].

As fracture displacement anterior to the glenoid fossa frequently causes devascularization of the humeral head, the risk of nonunion and osteonecrosis in a primary head-preserving treatment is high $[7,13]$. While early reports by Neer stated satisfactory outcomes following arthroplasty for acute three- and four-part fractures [13], HSA has often been favored over ORIF [3, 13] in anterior fracture dislocations. However, more recent studies suggest that functional results following HSA are often suboptimal [12, 14, 24]. In comparison with arthroplasty, successful ORIF offers the prospect of an improved functional outcome and the possibility that the development of osteonecrosis may be incomplete or relatively asymptomatic [25] and complete revascularization of the humeral head may occur through creeping substitution [26].

The most important finding of our study is that ORIF of anterior fracture dislocation can result in excellent outcomes. Owing to the devascularization of the humeral head, the risk of AVN is high; nonetheless, as seen from this study, not all fractures developed avascular necrosis following ORIF. In fact, it is still debatable which fractures develop AVN and correct prediction prior to surgery is limited. In our study, AVN was observed in $4.5 \%$ of type I fractures, but in $33 \%$ of type II fractures according to the classification by Robinson. Our findings confirm the results reported by Robinson et al., showing that in type I fractures, the occurrence of AVN is less likely than in type II injuries. We therefore suggest ORIF in young patients with a type I injury, since it may lead to excellent outcomes with a low risk of AVN. 


\section{Originalarbeit}

Table 1 Complication and revision rates after ORIF, HSA, and RSA for anterior fracture disloca-

$$
\text { tions }
$$

\begin{tabular}{llll} 
Procedure & $\boldsymbol{n = 8 1} \boldsymbol{n}(\%)$ & Complications (\%) & Revisions (\%) \\
\hline ORIF & $40(49.4)$ & $9 / 22.5$ & $6 / 15.0$ \\
HSA & $19(12.3)$ & $7 / 36.8$ & $4 / 21.0$ \\
RSA & $22(27.2)$ & $3 / 13.6$ & $0 / 0$
\end{tabular}

ORIF open reduction and internal fixation, HSA hemiarthroplasty, $R S A$ reverse shoulder arthroplasty

Table 2 Complications and revision surgeries following ORIF, HSA, and RSA in 81 patients with anterior fracture dislocations

\begin{tabular}{|c|c|c|}
\hline ORIF & HSA & RSA \\
\hline \multicolumn{3}{|l|}{ Complications } \\
\hline $\begin{array}{l}\text { Secondary displacement: } \\
2(5 \%)\end{array}$ & $\begin{array}{l}\text { Secondary tubercle dislocation: } \\
4(21.1 \%)\end{array}$ & Fracture of acromion: 1 (4.5\%) \\
\hline AVN: 7 (17.5\%) & Tubercle resorption: 2 (10.5\%) & $\begin{array}{l}\text { Secondary tubercle displace- } \\
\text { ment } 1(4.5 \%)\end{array}$ \\
\hline- & Septic loosening: 1 (5.3\%) & Tubercle resorption: 1 (4.5\%) \\
\hline \multicolumn{3}{|l|}{ Revision surgeries } \\
\hline $\begin{array}{l}1 \times \text { Revision osteosynthe- } \\
\text { sis }\end{array}$ & $3 \times$ Conversion to RSA & - \\
\hline $1 \times$ Conversion to has & $1 \times$ Tubercle re-fixation & - \\
\hline $3 \times$ Conversion to $\mathrm{RSA}$ & - & - \\
\hline
\end{tabular}

Importantly, as reported by others, outcomes following ORIF are related to the quality of the fracture reduction [27]. Therefore, if a head-preserving treatment is chosen, anatomic reduction should be achieved. To achieve anatomic reduction in anterior fracture dislocations, we prefer a deltopectoral approach with extension into the rotator interval to facilitate a cautious and anatomic fracture reduction. Commonly, a takedown of the long head of the biceps tendon is necessary and subsequent biceps tenodesis is performed. In terms of fracture fixation, we believe that a locking plate enables much more options for complex fracture patterns of the proximal humerus, than does nailing or other techniques; however, we are unable to prove this because plating was the only technique performed in this study.

In this study, functional outcomes following HSA were poor. In comparison, patients treated by primary RSA performed better and complications were less frequent. Similar to our study, Bonnevialle et al. found better results with RSA compared with HSA in displaced four-part fractures, although without comparing ORIF and RSA [19]. Independent of the fracture type, two studies showed better and more predictable functional results after RSA compared with HSA in acute proximal humeral fractures $[28,29]$. Because we observed patients performing better after RSA than patients treated by HSA, over time, the indications for HSA were reduced. Currently, we consider HSA in patients younger than 65 years only if fracture reduction is unsuccessful or a stable osteosynthesis cannot be achieved. Elderly patients (>65 years) with a type II anterior fracture dislocation are treated by RSA.

We believe that in the management of anterior fracture dislocations, early intervention is beneficial $[3,30]$. Our rate of AVN was lower (17.5\%) than that reported in other studies $[2,5,31]$. One reason may be that ORIF in anterior fracture dislocations was conducted within $24 \mathrm{~h}$ in all but one case. Trupka et al. reported that the displacement of the articular head fragment does not increase the risk of humeral head necrosis if treated by timely and careful ORIF [1]. Furthermore, Schnetzke et al. showed that in fracture dislocations of the proximal humerus, early surgery within $48 \mathrm{~h}$ of trauma significantly decreases the risk of AVN and subsequent surgery [32]. Apart from AVN, neurovascular damage seems to be another reason for timely intervention. The risk of brachial plexus and axillary artery lesions is increased in anterior fracture dislocations. Care must be taken not to cause further harm to the brachial plexus during fracture reduction. Presently, in our institution a fracture dislocation of the proximal humerus is treated as an emergency; thus, headpreserving treatment, whenever suitable, is performed in a timely fashion by the orthopedic trauma surgeon on call. However, in elderly patients with anterior fracture dislocation where RSA is intended, surgical intervention may be delayed until a surgeon familiar to reverse shoulder arthroplasty is present, so as to achieve the best results, nevertheless injury to the axillary nerve has to be ruled out by physical examination prior to surgery.

\section{Limitations}

Our study has several limitations. First, this is a retrospective cohort study comparing functional outcomes of different treatment options. Thus, the heterogeneity in results may be biased by treatment selection. Patients who underwent ORIF were significantly younger, and functional outcomes were likely to be better in comparison with elderly patients who were selected for arthroplasty. However, functional outcome was compared by means of an age- and gendernormalized Constant score. Secondly, surgeries were performed by 12 different surgeons over a period of 14 years. Thus, there may be heterogeneity in results due to the individual surgical technique. Fracture dislocation is rare; hence, individual experience in treating these fractures is different. However, all surgeries were performed according to general guidelines and all surgeons were board certified with a broad experience in the treatment of articular fractures. A bias in the functional results may be due to the timing of surgery, which was longer in arthroplasty compared with ORIF. Recovery may have 
been impaired if treatment was delayed. Given the rarity of this injury, it would require a large multicenter, randomized controlled trial to adequately compare the different treatment techniques and investigate the timing of interventions in anterior fracture dislocations of the proximal humerus.

\section{Practical conclusion}

- Treatment of anterior fracture dislocations is demanding.

- Open anatomic reduction and internal fixation can lead to excellent functional outcomes in young patients with good bone quality. Particularly in young patients with a Robinson type I injury, ORIF should be attempted at its best as soon as possible.

- By contrast, elderly and frail patients may profit from RSA as a primary treatment, performed in a timely manner by a surgeon familiar with shoulder arthroplasty.

- Hemiarthroplasty should be reserved for patients younger than 65 years, where the attempt of anatomic reduction and stable fixation has failed; however, functional outcomes are poor.

\section{Corresponding address}

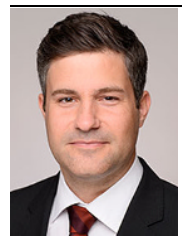

Ben Ockert, MD

Sektion Schulter- und Ellenbogenchirurgie, Klinik für Allgemeine, Unfall- und Wiederherstellungschirurgie, Klinikum der Universität München, LudwigMaximilians-Universität Nussbaumstr. 20, 80336 Munich, Germany ben.ockert@med.unimuenchen.de

\section{Compliance with ethical guidelines}

Conflict of interest M. Schirren, G. Siebenbürger E. Fleischhacker, N. Biermann, T. Helfen, W. Böcker, and B. Ockert declare that they have no competing interests.

All procedures followed were in accordance with the ethical standards of the responsible committee on human experimentation (institutional and national) and with the Helsinki Declaration of 1975 (in its most recently amended version). The ethics committee of the Ludwig Maximilian University of Munich approved the study (Nr. 156-12). Informed consent was obtained from all patients included in the study.

Open Access. This article is distributed under the terms of the Creative Commons Attribution 4.0 International License (http://creativecommons.org/licenses/by/ 4.0/), which permits unrestricted use, distribution, and reproduction in any medium, provided you give appropriate credit to the original author(s) and the source, provide a link to the Creative Commons license, and indicate if changes were made.

\section{References}

1. Trupka A et al (1997) Dislocated multiple fragment fractures of the head of the humerus. Does dislocation of the humeral head fragment signify a worse prognosis? Unfallchirurg 100(2):105-110

2. Erasmo R, Guerra G, Guerra L (2014) Fractures and fracture-dislocations of the proximal humerus: a retrospective analysis of 82 cases treated with the philos((R)) locking plate. Injury 45(Suppl6):S43-8

3. Hertel R et al (2004) Predictors of humeral head ischemia after intracapsular fracture of the proximal humerus. J Shoulder Elbow Surg 13(4):427-433

4. Court-Brown CM, Garg A, McQueen MM (2001) The epidemiology of proximal humeral fractures. Acta Orthop Scand 72(4):365-371

5. Hente Ret al (2004) Treatment of dislocated 3-and 4-part fractures of the proximal humerus with an angle-stabilizing fixation plate. Unfallchirurg 107(9):769-782

6. Robinson CM, Khan LA, Akhtar MA (2006) Treatment of anterior fracture-dislocations of the proximal humerus by open reduction and internal fixation. JBone Joint Surg Br 88(4):502-508

7. Hersche O, Gerber C (1994) latrogenic displacement of fracture-dislocations of the shoulder. A report of seven cases. J Bone Joint Surg Br 76(1):30-33

8. Emond $\mathrm{M}$ et al (2004) Clinical factors predicting fractures associated with an anterior shoulder dislocation. Acad Emerg Med 11(8):853-858

9. Ferkel RD, Hedley AK, Eckardt JJ (1984) Anterior fracture-dislocations of the shoulder: pitfalls in treatment. J Trauma 24(4):363-367

10. Wronka KS, Ved A, Mohanty K (2017) When is it safe to reduce fracture dislocation of shoulder under sedation? Proposed treatment algorithm. Eur J OrthopSurg Traumatol 27(3):335-340

11. Menendez ME, Ring D, Heng M (2015) Proximal humerus fracture with injury to the axillary artery: a population-based study. Injury 46(7):1367-1371

12. Kralinger $F$ et al (2004) Outcome after primary hemiarthroplasty for fracture of the head of the humerus. A retrospective multicentre study of 167 patients. J Bone Joint Surg Br 86(2):217-219

13. Neer CS 2nd (1970) Displaced proximal humeral fractures. II. Treatment of three-part and fourpart displacement. J Bone Joint Surg Am 52(6):1090-1103

14. Boileau P et al (2002) Tuberosity malposition and migration: reasons for poor outcomes after hemiarthroplasty for displaced fractures of the proximal humerus. J Shoulder Elb Surg 11(5):401-412
15. Olerud $P$ et al (2011) Hemiarthroplasty versus nonoperative treatment of displaced 4-part proximal humeral fractures in elderly patients: a randomized controlled trial. J Shoulder Elbow Surg 20(7):1025-1033

16. Boons HW et al (2012) Hemiarthroplasty for humeral four-part fractures for patients 65 years and older: a randomized controlled trial. Clin Orthop Relat Res 470(12):3483-3491

17. Soliman OA, Koptan WM (2013) Four-part fracture dislocations of the proximal humerus in young adults: results of fixation. Injury 44(4):442-447

18. Anakwenze OA et al (2014) Reverse shoulder arthroplasty for acute proximal humerus fractures: a systematic review. J Shoulder Elbow Surg 23(4):e73-80

19. Bonnevialle N et al (2016) Hemiarthroplasty versus reverse shoulder arthroplasty in 4-part displaced fractures of the proximal humerus: multicenter retrospective study. Orthop Traumatol Surg Res 102(5):569-573

20. Han RJ et al (2016) Proximal humerus fragility fractures: recent trends in nonoperative and operative treatment in the Medicare population. JShoulder Elbow Surg 25(2):256-261

21. Erdle B et al (2018) Primary fracture protheses and reverse shoulder arthroplasty in complex humeral head fractures: an alternative to joint-preserving osteosynthesis? Orthopade 47(5):410-419

22. Ockert B et al (2014) Long-term functional outcomes (median 10 years) after locked plating for displaced fractures of the proximal humerus. $J$ Shoulder Elbow Surg 23(8):1223-1231

23. Ockert B et al (2010) Monoaxial versus polyaxial screw insertion in angular stable plate fixation of proximal humeral fractures: radiographic analysis of a prospective randomized study. J Trauma 69(6):1545-1551

24. Robinson CMetal (2003) Primary hemiarthroplasty for treatment of proximal humeral fractures. JBone Joint Surg Am 85-A(7):1215-1223

25. Wijgman AJ et al (2002) Open reduction and internal fixation of three and four-part fractures of the proximal part of the humerus. JBone Joint Surg Am 84-A(11):1919-1925

26. Kofoed $H$ (1983) Revascularization of the humeral head. A report of two cases of fracture-dislocation of the shoulder. Clin Orthop Relat Res 179:175-178

27. Schnetzke M et al (2016) Quality of reduction influences outcome after locked-plate fixation of proximal humeral type-C fractures. J Bone Joint Surg Am 98(21):1777-1785

28. Sebastia-Forcada E et al (2014) Reverse shoulder arthroplasty versus hemiarthroplasty for acute proximal humeral fractures. A blinded, randomized, controlled, prospective study. J Shoulder Elbow Surg 23(10):1419-1426

29. Boyle MJ et al (2013) Functional outcomes of reverse shoulder arthroplasty compared with hemiarthroplasty for acute proximal humeral fractures. J Shoulder Elbow Surg 22(1):32-37

30. Siebenburger $\mathrm{G}$ et al (2015) Timing of surgery for open reduction and internal fixation of displaced proximal humeral fractures. Injury 46 (Suppl 4):S58-S62

31. Spross C et al (2012) Surgical treatment of Neer Group VI proximal humeral fractures: retrospective comparison of PHILOS(R) and hemiarthroplasty. Clin Orthop Relat Res 470(7):2035-2042

32. Schnetzke $M$ et al (2018) Rate of avascular necrosis after fracture dislocations of the proximal humerus: timing of surgery. Obere Extremität 13(4):273-278. https://doi.org/10.1007/s11678018-0452-6 